\title{
Pseudo aneurysm of uterine artery and cesarean scar dehiscence causing secondary post-partum haemorrhage managed by uterine artery embolisation: a case report
}

\author{
Kalpana Singh $^{1}$, Geetam Bharati ${ }^{1}$, Smita Kumari $^{1}$, Nishant Tripathy $^{2}$
}

\footnotetext{
${ }^{1}$ Department of Obstetrics and Gynecology, Indira Gandhi Institute of Medical Sciences, Patna, Bihar, India

${ }^{2}$ Department of Cardiology, Indira Gandhi Institute of Medical Sciences, Patna, Bihar, India
}

Received: 06 June 2016

Accepted: 01 July 2016

\author{
*Correspondence: \\ Dr. Kalpana Singh, \\ E-mail: drkalpana1@yahoo.com
}

Copyright: () the author(s), publisher and licensee Medip Academy. This is an open-access article distributed under the terms of the Creative Commons Attribution Non-Commercial License, which permits unrestricted non-commercial use, distribution, and reproduction in any medium, provided the original work is properly cited.

\begin{abstract}
Uterine artery pseudo aneurysm is rare but potentially life threatening complication of cesarean section and may present with severe secondary postpartum haemorrhage. Here we report a case of secondary postpartum haemorrhage due to pseudo aneurysm of left uterine artery and cesarean scar dehiscence in 27 yrs old women which was managed successfully with uterine artery embolisation at IGIMS, Patna. These 27 yrs old young women presented with severe secondary PPH forty days following cesarean section. Ultrasound and CT scan abdomen was done which showed full thickness defect in the lower segment of uterus and focal enhancement in the early arterial and late venous phase in left parametrium. Pseudo aneurysm being rare was not suspected and patient underwent laparotomy. Twenty two days after surgery patient again had heavy bout of vaginal bleeding. Doppler Ultrasound was done which showed large pseudo aneurysm of left uterine artery which was then managed successfully with uterine artery embolisation. Although rare but pseudo aneurysm of uterine artery should be suspected in case of secondary PPH where other common causes has been excluded. Angiographic embolisation of uterine artery is safe and effective method for treating secondary PPH due to pseudo aneurysm of uterine artery in haemodynamically stable patient. Therefore, in modern obstetrics hysterectomy should be the last option to treat postpartum haemorrhage.
\end{abstract}

Keywords: Scar dehiscence, Pseudo aneurysm of uterine artery, Secondary post-partum haemorrhage embolisation

\section{INTRODUCTION}

$\mathrm{PPH}$ is the leading cause of maternal mortality in developing countries. Incidence of PPH is around 5$10 \% .^{1,2}$ Primary PPH is more common than secondary $\mathrm{PPH}$. Also primary PPH causes more mortality than secondary PPH. Overall incidence of secondary $\mathrm{PPH}$ in developed world varies from $0.47 \%$ to $1.44 \% .^{3,4}$ Secondary PPH causes more morbidity than mortality. However severe secondary PPH may sometimes become fatal. Pseudo aneurysm of uterine artery and cesarean scar dehiscence are rare causes of secondary post-partum hemorrhage. Development of arterial pseudo aneurysm is rare but reported complication of pelvic surgery, vascular trauma during cesarean section or after uterine curettage. After hematoma formation there is central liquefaction that leaves a cavity with turbulent blood flow as a result of persistent communication between the parent artery and the hematoma. Absence of three layered arterial wall lining pseudo aneurysm differentiates it from true aneurysm which is less common than pseudo aneurysm. ${ }^{5}$ Secondary PPH may occur due to rupture of pseudo aneurysm which depends upon size and intramural pressure. Diagnosis is usually made on USG and angiography. Uterine artery embolisation is an effective method to control hemorrhage in haemodynamically stable patient. 
Herein we report a case of secondary post-partum hemorrhage in a 27 years old P2L2 woman 40 days after cesarean section due to scar dehiscence and pseudo aneurysm of uterine artery which was managed successfully with uterine artery embolisation.

\section{CASE REPORT}

27 yrs old P2L2 was referred to our institution 40 days after cesarean section with history of excessive vaginal bleeding and haematuria since one day. Vaginal bleeding had stopped spontaneously after 2 hours but haematuria was continuing. She had undergone an elective LSCS in view of previous LSCS 40 days back and delivered an alive male baby of birth weight $3.6 \mathrm{Kg}$. On $40^{\text {th }}$ postoperative day she experienced heavy bleeding per vagina and was readmitted in private nursing home where she was stablished with crystalloid and two units of packed cell transfusion was done. She was investigated with USG and CECT abdomen which showed wound dehiscence with full thickness defect in the lower segment of uterus and adjacent cervix with surrounding hematoma of size about $9.6 * 8.7 * 7.0 \mathrm{~cm}$ and volume 300 $\mathrm{ml}$. Large amount of clot was seen in the urinary bladder. There was focal intense enhancement in the late arterial and early venous phase in left parametrium suggestive of active bleeding. With these findings patient was referred to our institution. After routine and preoperative workup emergency laparotomy was done. Dense adhesions were present between omentum, bladder and anterior wall of uterus .Adhesiolysis was done .Large organised blood clot was present in between the lower segment of uterus and urinary bladder which was removed and there was full thickness dehiscence in the caesarean section wound in the lower segment of anterior uterine wall. Wound debridement followed by repair of uterine wall by interrupted mattress stitches was done. Bladder wall was intact, bladder wash was done. Intraperitoneal drain put, abdomen closed. Foleys catheterisation was done. Intraperitoneal drain was productive for almost 10 days. On post-operative day 22 she had again heavy bout of bleeding per vagina. Uterotonics and blood transfusion was given. Again USG was done which revealed $24 \mathrm{~mm} \times$ $21 \mathrm{~mm}$ sized cystic lesion anterior to cervix with intense colour flow suggestive of aneurysm formation. Immediate angiography was done which showed a large pseudo aneurysm arising from a branch of left uterine artery. Left uterine artery embolization was done. Post embolization there was no blood flow and pseudo aneurysm was not visible.

\section{DISCUSSION}

UAP is a rare but life threatening complication of uterine surgery especially caesarean section. ${ }^{6,7}$ Rupture of pseudo aneurysm results in secondary PPH. Extension of uterine incision and additional haemostatic suture may be associated with occurrence of UAP after caesarean section. Severe secondary PPH is the most common presentation of UAP, but it may remain asymptomatic or may thrombose or may lead to distal painful embolisation. When rupture is limited by surrounding tissue it may cause intermittent bleeding. When hemorrhage is confined to abdominal cavity it may present as abdominal pain (8). Incidence of cesarean scar dehiscence is $0.3-1.9 \%$ and PPH due to CSD is rarely reported. ${ }^{9,10}$ Gray scale USG is the initial non-invasive diagnostic tool which reveals a hypoechoic mass associated with uterine incision. Color and pulsed Doppler USG may show characteristic to and fro pattern in the neck and "yin yang sign" in the body of UAP with diagnostic sensitivity of $95 \% .^{11,12} \mathrm{CT}$ and MRI may help to confirm diagnosis and also to rule out other common causes of secondary PPH. Angiography remains the gold standard diagnostic method with advantage of designing the definitive treatment strategy. ${ }^{13}$

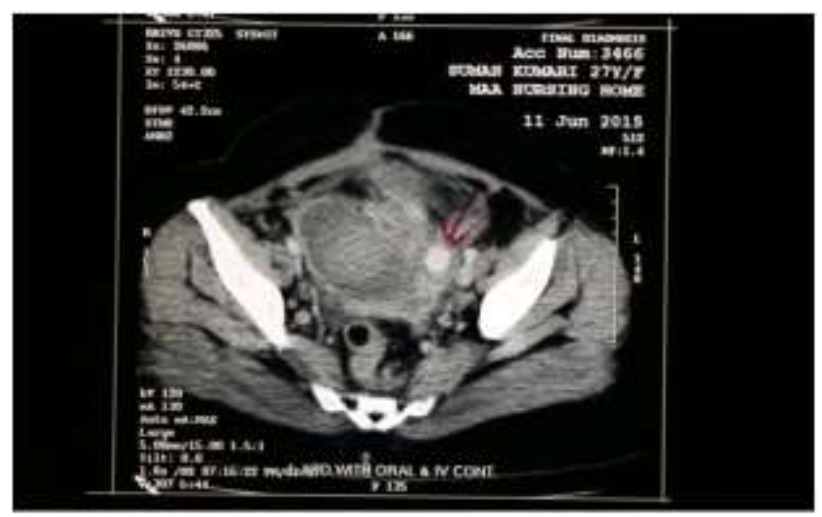

Figure 1: CECT showing focal intense enhancement in the late arterial and early venous phase in the left parametrium (Pre embolisation).

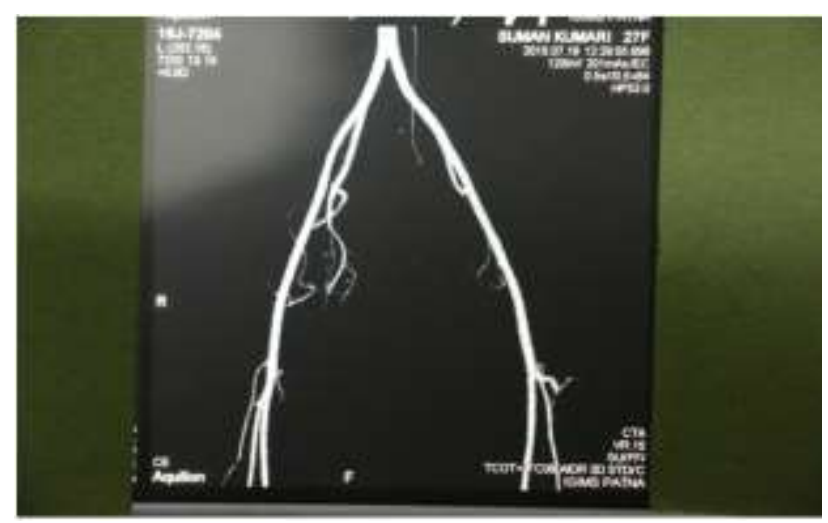

Figure 2: Post uterine artery embolisation CECT showing blocked left uterine artery.

Recently 3D power Doppler imaging has been used to diagnose UAP. Success rate following embolisation is 97\%. Recent reports described the use of thrombin injection directly into the pseudo aneurysm under ultrasound guidance, as a substitute for arterial embolisation, however its indication and effectiveness have not yet described. ${ }^{14}$ 
Uterine artery embolisation offers the advantage of localization of exact bleeding site, decreased morbidity and duration of hospital stay, more distal occlusion than surgical ligation of artery, no need of general anesthesia, repeat embolisation if needed can be performed and preservation of future fertility.

In 1979 Brown et al reported the first case of selective arterial embolisation used successfully to treat an extra uterine pelvic hematoma after 3 failed surgical attempts to control the bleeding, since that time arterial embolisation has been used successfully to control postpartum bleeding due to atony, placenta accreta, extrauterine pregnancies and vulval and vaginal hematoma. ${ }^{15}$

Recently there have been few articles citing UAP after caesarean section as a rare cause of secondary PPH. Nanjundan $P$ et al have reported a similar case of secondary PPH on $19^{\text {th }}$ post-operated day and was treated by embolisation. ${ }^{16} \mathrm{UAE}$ for obstetrics related hemorrhage was done in 76 women by Ganguli S et al, in 16 women for secondary PPH. Among these 3 were diagnosed as case of pseudo aneurysm of uterine artery. All 3 were delivered by caesarean section. ${ }^{17}$ Chita TV from Coimbatore have analysed 5 cases of secondary PPH presented between $3^{\text {rd }}$ to $6^{\text {th }}$ week post caesarean section and diagnosed to have pseudo aneurysm by angiography. 4 patients were managed by UAE, 1 patient had undergone hysterectomy. ${ }^{18}$ Dadhwal $\mathrm{V}$ et al had reported case of co-existent A-V malformation and pseudo aneurysm who presented with secondary PPH 37days after emergency caesarean section which was managed by UAE. Patient needed repeat embolisation. ${ }^{19}$ Pelage et al had managed 14 cases of secondary PPH with embolisation in which 2 were case of pseudo aneurysm. ${ }^{20}$ In most of the cases unilateral embolisation may suffice, but sometimes if bleeding persists due to redistribution from opposite side bilateral embolisation may be performed. Chita TV et al and Cooper et al have reported cases of UAP presenting as secondary PPH who required bilateral uterine artery embolisation. ${ }^{21}$ Similar to our case where secondary PPH was due to co-existent UAP and CSD, Yeniel AO et al from Turkey reported a case in 2013 where secondary PPH was due to coexistent UAP and CSD. They claimed it to be the first reported case of co-existent UAP and CSD which was managed by uterine artery ligation. $^{22}$

\section{CONCLUSION}

Although rare but pseudo aneurysm of uterine artery should be suspected in cases of secondary $\mathrm{PPH}$ where other common causes has been excluded, especially after caesarean section. Doppler USG and angiography are useful techniques to diagnose pseudo aneurysm. Angiographic embolisation is safe and effective procedure in haemodynamically stable patients. However, uterine artery ligation may be surgical procedure of choice in haemodynamically unstable patient when preservation of fertility is desired. With newer modalities of treatment available hysterectomy should be the last resort to treat $\mathrm{PPH}$.

Funding: No funding sources

Conflict of interest: None declared

Ethical approval: Not required

\section{REFERENCES}

1. Fullerton G, Danielian PJ, Bhattacharya S. Outcomes of pregnancy following post-partum hemorrhage. British J of Obstet Gynaecol. 2013;120(5):621-7.

2. Carroli G, Cuesta C, Abalos E, Gulmezoglu AM. Epidemiology of post-partum hemorrhage: a systematic review. Best Practice Res Clin Obstet Gynaecol. 2008;22(6):999-1012.

3. Hoveyda F, Mackenzie IZ. Secondary post-partum hemorrhage: incidence, morbidity and current management. Br J Obstet Gynaecol. 2001;108:92730 .

4. King PA, Duthie SJ, Dong ZG. Secondary postpartum hemorrhage. Aust NZ J Obstet Gynaecol. 1989;29:394-8.

5. Kwon JH, Kim GS. Obstetric iatrogenic arterial injuries of the uterus: Diagnosis with ultrasound and treatment with transcatheter arterial embolisation. Radiographics. 2002;221:35-46.

6. Descargues G, Douvrin F, Gravier A. False aneurysm of the uterine pedicle: an uncommon cause of post-partum hemorrhage after cesarean section treated with selective arterial embolisation. European $\mathrm{J}$ of Obstetrics Gynecology and Reproductive Biology. 2001;97(1):26-9.

7. Eason DE, Tank RA. Avoidable morbidity in a patient with pseudo aneurysm of the uterine artery after cesarean section. Journal of clinical ultrasound. 2006;34(8):407-11.

8. Kuwata T, Matsubara S, Kaneko, Izumi A, Nakata M, Suzuki M. Asymptomatic uterine artery pseudoaneurysm after cesarean section. Journal of Obstetrics and Gynecology Research. 2010;36(2):405-10.

9. Erickson SS, Van Voorhis BJ. Intermenstrual bleeding secondary to cesarean scar diverticulli: report of three cases. Obstetrics and Gynaecology. 1999;93(5):802-5.

10. Baba T, Morishita M, Nagata M, Yamakawa Y, Mizunuma M. Delayed post-partum hemorrhage due to cesarean scar dehiscence. Archieves of Gynecology and Obstetrics. 2005;272(1):82-3.

11. Butori N, Laurène C, Laurence F. Pseudo aneurysm of uterine artery after cesarean delivery: management with superselective arterial embolisation. Obstetrics and Gynaecology. 2009;113(2):540-3.

12. Polat P, Suma S. Color Doppler ultrasound in the evaluation of uterine vascular abnormalities, Radiographic. 2002;22(1):47-53.

13. Vedanatham S, Goodwin SC, McLucas B. Uterine artery embolisation. An underused method of 
controlling pelvic hemorrhage. Am J Obstet Gynaecol. 1997;176:938-48.

14. Kovo M, Behar DJ, Friedman V. Pelvic arterial pseudoaneurysm- a rare complication of cesarean section: Diagnosis and novel treatment. Ultrasound in Obstetrics and Gynecology. 2007;30(5):783-5.

15. Brown BJ, Heaston DK, Paulson AM, et al. Uncontrollable postpartum bleeding; a new approach to hemostasis through angiographic embolisation. Obstet Gynaecol. 1979;188: 183-187.

16. Nanjundan $P$, Rohilla $M$, Raveendran A. Pseudoaneurysm of uterine artery: a rare cause of secondary postpartum hemorrhage, managed with uterine artery embolisation. J Clin Imaging Sci. 2011;1:14.

17. Ganguli S, Stecker MS. Uterine artery embolisation in the treatment of postpartum uterine hemorrhage .J Vasc Interv Radiol. 2011;22:169-76.

18. Chitra TV, Panicker S. Pseudo aneurysm of uterine artery: A rare cause of Secondary Postpartum Hemorrhage. Journal of Obstet and Gynaecol of India. 2011;61(6):641-4.

19. Dadhwal V, Gupta B, Srivastava DN, Deka D, Mittal S. Uterine Artery Pseudoaneurysm with AV
Malformation:A Rare Cause of Secondary PostPartum Haemorrhage. Journal of Medical Education and Research. 2007;9(3):142-4.

20. Pelage JP, Soyer P, Repiquet D. Secondary postpartum hemorrhage: treatment with selective arterial embolisation. Radiology. 1999;212:385-9.

21. Cooper BC, Hocking-Brown M, Sorosky JI. Pseudoaneurysm of the uterine artery requiring bilateral uterine artery embolisation. J Perinatol. 2004;24:560-2.

22. Yenial AO Ergenoglu AM, Akdemir A. Massive Secondary Postpartum Hemorrhage with Uterine Artery pseudo aneurysm after Cesarean Section. Case Reports in Obstetrics and Gynecology. 2013, Article ID 285846, 4 pages.

Cite this article as: Singh $\mathrm{K}$, Bharati G, Kumari S, Tripathy N. Pseudo aneurysm of uterine artery and cesarean scar dehiscence causing secondary postpartum haemorrhage managed by uterine artery embolisation: a case report. Int J Reprod Contracept Obstet Gynecol 2016;5:2895-8. 